\title{
BMJ Open Quality Redesigned intravenous fluid order form with more perceived safety and accuracy for after-hours doctors
}

\author{
Christene Mikhail, ${ }^{1,2}$ Jeffrey Ha, ${ }^{1,3}$ Shraddha Banthia, ${ }^{1}$ Ivan Liu, ${ }^{1}$ Elizabeth Tenney, ${ }^{1}$ \\ Daniel Tardo, ${ }^{1}$ George Rubin, ${ }^{4}$ Justine Harris ${ }^{1,2}$
}

To cite: Mikhail C, Ha J, Banthia S, et al. Redesigned intravenous fluid order form with more perceived safety and accuracy for after-hours doctors. BMJ Open Quality 2019;8:e000379. doi:10.1136/ bmjoq-2018-000379

- Additional material is published online only. To view, please visit the journal online (http://dx.doi.org/10. 1136bmjoq-2018-000379).

$\mathrm{CM}$ and $\mathrm{JH}$ contributed equally.

Received 17 March 2018 Revised 19 February 2019 Accepted 21 May 2019

Check for updates

(C) Author(s) (or their employer(s)) 2019. Re-use permitted under CC BY-NC. No commercial re-use. See rights and permissions. Published by BMJ.

${ }^{1}$ Department of Medicine, St George Hospital, Kogarah, Sydney, New South Wales, Australia

${ }^{2}$ Department of Surgery, The Sutherland Hospital, Caringbah, Sydney, New South Wales,

Australia

${ }^{3}$ Department of Medicine, St George and Sutherland Clinical School, University of New South Wales, Sydney, New South

Wales, Australia

${ }^{4}$ School of Public Health, University of Sydney, Sydney, New South Wales, Australia

Correspondence to Christene Mikhail;

Christene.Mikhail@health.nsw. gov.au

\section{INTRODUCTION}

Intravenous fluid (IVF) is often prescribed by doctors of the treating teams during daytime hours for various indications. At present, the New South Wales (NSW) IVF order form $^{1}$ (online supplementary figure 1) does not include explicit documentation of the indication for prescribing IVF. As a result, the after-hours doctor is often requested to chart further IVF without knowledge of the patient's condition or the indication for IVF.

As many as one in five patients suffer complications from inappropriate IVF prescribing. ${ }^{2}$ Patients with heart failure or liver cirrhosis are more vulnerable to fluid overload with excessive IVF therapy. ${ }^{34}$ Conversely, acute kidney injury is a complication of inadequate IVF prescribing. ${ }^{3}$ Other adverse effects include electrolyte imbalances potentiating the risk of life-threatening arrhythmias. ${ }^{5}$ The time constraints during a busy after-hours shift can further compromise the accuracy and safety of charting IVF for unfamiliar patients.

To overcome these barriers, we developed a revised IVF order form (online supplementary figure 2) which clearly documents the indication for IVF, the fluid restriction status and comorbidities of the patient. These simple yet critical additions will enable the IVF order form to be a useful tool in the handover of a 'fluid plan' for patients, between the daytime medical teams and afterhours medical and nursing staff. It will aim to assist the after-hours doctor in the safety and accuracy of prescribing IVF.

\section{METHODS}

The original IVF order form ${ }^{1}$ was redesigned to include relevant patient information for safe prescribing of IVF. This included the following new sections: indication for IVF, fluid restriction status and tick boxes for relevant patient comorbidities, including diabetes, heart, liver and renal failure (online supplementary figure 2). Approval to trial the revised form (deemed very low risk in causing any patient harm) was gained from the NSW State Forms Committee and local health district council.

Following medical and nursing staff education (online supplementary figure 3), the revised form was trialled in a surgical ward at The Sutherland Hospital (TSH) and a medical ward at St George Hospital (SGH) with deidentified data collated over a 2-week period. During the trial period, medical and nursing staff $(\mathrm{n}=84)$ were approached to complete surveys, and all participated with their informed consent. The qualitative surveys with 'yes/no' responses from medical and nursing staff $(n=84)$ assessed the following: whether the revised IVF order form was easy to use, whether the new sections of the revised form were useful and if having the indication helped doctors chart IVF more safely. ${ }^{6}$ Compliance with filling out the new sections of the revised IVF order form was also audited over the 2-week trial period.

The time required by an after-hours doctor to chart IVF safely for 20 patients was audited preimplementation and postimplementation of the revised IVF order form. Simple descriptive analysis was conducted using Excel.

\section{RESULTS}

All 84 medical and nursing staff who completed the survey reported that the revised IVF order form would be easy to use. All medical and nursing staff also found the additional documentation of the indication for IVF and fluid restriction status to be useful during an after-hours shift. The inclusion of tick boxes for common comorbidities that may influence IVF prescribing was found to be useful by $89 \%$ of medical and nursing staff.

Ninety-two percent of after-hours doctors $(n=40)$ surveyed had been asked to chart IVF 
without knowledge of the indication for IVF or comorbidities of the patient. Ninety-two percent also felt that having the indication for IVF documented by the treating team during the day helped them chart IVF more safely, in the after-hours period for unfamiliar patients.

Compliance with using the revised IVF order form was $83 \%$ and $80 \%$ at SGH and TSH, respectively, during the 2-week trial period. Where the revised IVF order form was used, $91 \%$ at TSH and $87 \%$ at SGH had the indication for IVF appropriately documented. The fluid restriction status was documented on $33 \%$ and $44 \%$ of forms at TSH and SGH, respectively. The tick boxes for comorbidities were used considerably less in the surgical ward at TSH compared with SGH, at $6 \%$ and $83 \%$, respectively.

Preimplementation of the revised form, the mean time required by an after-hours doctor to safely prescribe IVF for each patient was $3 \mathrm{~min}$ (range: $1 \mathrm{~min} 57 \mathrm{~s}-7 \mathrm{~min} 58$ s), which included time to source all the relevant information. This equated to $60 \mathrm{~min}$ for 20 patients during an after-hours shift at SGH. Postimplementation, the mean time required by an after-hours doctor to chart IVF safely with the information readily available on the form was $30 \mathrm{~s}$ (range: $19 \mathrm{~s}-46 \mathrm{~s}$ ). This equates to $10 \mathrm{~min}$ for 20 patients, accounting for the time to acquire information that was not included on the revised form (eg, serum biochemistry and renal function).

\section{DISCUSSION}

Alarmingly, our surveys revealed that nearly all after-hours doctors have been asked to chart IVF without knowledge of the indication for IVF or the patient's comorbidities. The surveys also indicated that the revised IVF order form helped doctors chart IVF more safely for unfamiliar patients during the after-hours period.

The feedback from medical and nursing staff regarding the revised IVF order form was very positive. From the survey responses, it could be inferred that medical and nursing staff considered the revised form a simple yet useful tool to handover a 'fluid plan' to after-hours doctors and nurses.

Further comments from survey responders acknowledged that if multiple comorbidities were flagged for a patient, the patient may not receive any IVF, even when warranted. Our aim, however, was to ensure that a considered approach was taken when prescribing IVF to patients with multiple comorbidities given their increased risk of fluid-related complications. ${ }^{3-5}$

During the trial period, a considerable proportion of IVF order forms had the fluid restriction status and tick boxes for comorbidities not filled in. This could be explained by a proportion of patients who in fact had no comorbidities or fluid restrictions. This prompted the addition of an extra tick box for 'Nil' adjacent to the fluid restriction status and comorbidities section of the trialled IVF order form. When used, the 'Nil' tick boxes would clearly demonstrate that the patient's lack of a fluid restriction or relevant comorbidities had already been acknowledged by a treating doctor.

The tick boxes for relevant comorbidities were minimally used in a surgical ward at TSH. This could be explained by many surgical patients with short admissions, who only required IVF while fasted and were unlikely to require IVF in the after-hours period; in which case, handover of a patient's comorbidities or fluid restriction status became less essential. Furthermore, the day surgery patients may have had a lower comorbidity burden compared with complex patients in a medical ward at SGH.

A limitation of our study was that the revised form was trialled for a short period of time in a surgical and a medical ward, and did not include other areas of the hospital (eg, emergency department and intensive care unit). Furthermore, the benefits of the revised form will depend on compliance with filling out all sections of the form, demonstrated to be variable during our audit. However, the transition to electronic IVF ordering may improve compliance through built-in prompts for doctors.

A future transition to electronic IVF ordering may improve compliance with completing new sections of our revised form, through built-in electronic prompts for doctors to flag a patient's comorbidities or fluid restriction status. We also plan to propose a strict IVF prescribing policy of 'no indication, no fluids', such that nurses will be trained not to administer IVF without full documentation.

\section{CONCLUSION}

The revised IVF order form is a simple, time-saving approach to providing an effective handover to afterhours doctors. It enables them to feel assured that they are recharting IVF safely and appropriately for unfamiliar patients. Our project and data resulted in approval for use of the revised IVF order form state-wide. Further evaluation of the form will be required to determine if its introduction will reduce adverse outcomes from inappropriate IVF prescribing.

Contributors CM: project leader, conception of idea, study design, first author including drafting of the manuscript, critical revision and final approval of version to be published, facilitated audit at The Sutherland Hospital, data analysis and interpretation. JH: study design, contributed equally to drafting and critical revision of the manuscript, facilitated audit at St George Hospital. SB: design of updated intravenous fluid order form, contributed to audits at St George Hospital, drafting and critical revision of the manuscript. ET: design of poster and promotion materials for project, contributed to audits at St George Hospital. IL: contributed to audits and data collection at St George Hospital and The Sutherland Hospital. DT: contributed to audits and data collection at St George Hospital and The Sutherland Hospital. GR and $\mathrm{JH}$ : input into audits and study design, supervisors for project.

Funding The authors have not declared a specific grant for this research from any funding agency in the public, commercial or not-for-profit sectors.

Competing interests None declared.

Patient consent for publication Not required.

Ethics approval Approval to trial the redesigned intravenous fluid order form was gained from the State Forms Committee and local health district council. The conduct 
of the study was deemed very low risk in causing any patient harm and did not require a full Human Research Ethics Application. Deidentified data from the trialed intravenous fluid order form was collated.

Provenance and peer review Not commissioned; externally peer reviewed.

Open access This is an open access article distributed in accordance with the Creative Commons Attribution Non Commercial (CC BY-NC 4.0) license, which permits others to distribute, remix, adapt, build upon this work non-commercially, and license their derivative works on different terms, provided the original work is properly cited, appropriate credit is given, any changes made indicated, and the use is non-commercial. See: http://creativecommons.org/licenses/by-nc/4.0/.

\section{REFERENCES}

1. NSW State Forms Committee, NSW Ministry of Health. Adult fluid order form 2012

2. National Institute for Health and Care Excellence. Intravenous fluid therapy for adults in hospital. (clinical guideline 174), 2013. Available: www.nice.org.uk/CG174

3. Frost $P$. Intravenous fluid therapy in adult inpatients. $B M J$ 2014;350:7620.

4. Eastwood GM, Peck L, Young $\mathrm{H}$, et al. Intravenous fluid administration and monitoring for adult ward patients in a teaching hospital. Nurs Health Sci 2012;14:265-71.

5. Walsh SR, Walsh CJ. Intravenous fluid-associated morbidity in postoperative patients. Ann R Coll Surg Engl 2005;87:126-30.

6. Fehmi J, Carpenter A, Townsend M, et al. Out of hours intravenous fluid therapy: a prompt to guide prescribing. BMJ Qual Improv Rep 2015;4:u204010.w3139-638. 